\title{
Attenuation of kainic acid-induced epilepsy by butyrate is associated with inhibition of glial activation
}

\author{
Changquan Wang, Guangming Xia, Gang Li, Feng Wan, Yanwen Lv*, Zhanchi \\ Xiao \\ Department of Neurology, Huanggang Central Hospital, Huanggang 438000, China
}

*For correspondence: Email: Lvyanwhzcdoc@126.com

\begin{abstract}
Purpose: To investigate the function and potential therapeutic relevance of butyrate in epilepsy using rat models of kainic acid (KA)-induced epilepsy.

Methods: The neurotoxin KA was applied to rats and rat astrocytes to establish models of epilepsy in vivo and in vitro. Multiple parameters, including behavioural seizure scores, were evaluated in rats and rat astrocytes treated with KA alone or in combination with butyrate. Western blot was performed to examine the levels of phosphorylated extracellular signal-related kinase ( $p$-ERK), proinflammatory cytokine (IL-1B), and glial fibrillary acidic protein (GFAP).

Results: Significant increases were observed in the seizure-related proteins $p$-ERK and GFAP and in the proinflammatory cytokine IL-1B in KA-treated rats and rat astrocytes $(p<0.05)$. Butyrate treatment attenuated KA-induced epileptic behaviour in rats and significantly reduced the expression of $p-E R K$, GFAP, and IL-1B in a dose-dependent manner $(p<0.05)$.

Conclusion: Butyrate has potential as a treatment for epilepsy by inhibiting the activation of $p$-ERK, astrogliosis, and inflammation, which were induced by $K A$ in rats and rat astrocytes.
\end{abstract}

Keywords: Kainic acid, Epilepsy, Butyrate, Glial activation, Astrogliosis

\begin{abstract}
This is an Open Access article that uses a funding model which does not charge readers or their institutions for access and distributed under the terms of the Creative Commons Attribution License (http://creativecommons.org/licenses/by/4.0) and the Budapest Open Access Initiative (http://www.budapestopenaccessinitiative.org/read), which permit unrestricted use, distribution, and reproduction in any medium, provided the original work is properly credited.

Tropical Journal of Pharmaceutical Research is indexed by Science Citation Index (SciSearch), Scopus, International Pharmaceutical Abstract, Chemical Abstracts, Embase, Index Copernicus, EBSCO, African Index Medicus, JournalSeek, Journal Citation Reports/Science Edition, Directory of Open Access Journals (DOAJ), African Journal Online, Bioline International, Open-J-Gate and Pharmacy Abstracts
\end{abstract}

\section{INTRODUCTION}

Epilepsy is a neurological disorder that is accompanied by recurrent seizures due to abnormal hypersynchrony of neuronal activity [1]. Epilepsy poses significant health concerns, as it affects more than 50 million people worldwide [2]. Unfortunately, approximately $30 \%$ of patients with epilepsy fail to respond to currently available anti-epileptic drugs [3]. Patients with epilepsy have a life expectancy reduction of up to $2-10$ years compared with the general population [4].
It is critically important to identify and develop novel approaches with effective antiepileptogenic or disease-modifying effects [5].

Microglia is known to have neurotoxic and neuroprotective effects in central nervous system diseases [6]. Analyses of deceased humans and patients with intractable seizures demonstrated increases in microglial reactivity to a histocompatibility antigen as great as threefold and 11-fold in the conus ammon (CA) 3 and CA1 regions, respectively [7]. In addition, hippocampi 
of patients with epilepsy were found to contain inflammation-related molecules as well as activated microglia and astrocytosis [8]. The inflammation-related molecules, which were primarily released from microglia and astrocytes, resulted in epilepsy $[9,10]$. In addition, clinical and experimental evidence has demonstrated an association between epilepsy and inflammatory processes $[11,12]$.

To explore a potential therapeutic approach for epilepsy/seizures, this study aimed to investigate the function of butyrate in KA-induced epilepsy in male adult rats in vivo and rat astrocyte cells in vitro. The findings demonstrate that butyrate has potential as an agent for the treatment of kainic acid (KA)-induced seizures in animals and cultured cells. This finding should be further investigated in clinical settings.

\section{EXPERIMENTAL}

\section{Rats}

Adult male Sprague-Dawley (SD) rats 6-7 weeks of age and weighing 120-140 g were used for this research. The rats were fed in a room with controlled temperature and humidity and a controlled cycle of $12 \mathrm{~h}$ light/dark. The rats were acclimated to the new environment for approximately 7 days prior to the beginning of the experiments. Experiments were carried out in accordance with the international guidelines for animal studies about the care and use of animals for experiments [13] in Huanggang Central Hospital (approval no. SCXK-2015-0018).

\section{Drug treatment}

The neurotoxin $\mathrm{KA}$, which induces behavioural and electrophysiological seizures, was used in this study. Rats were treated with KA (Wako, Tokyo, Japan) to obtain a seizure model. The rats were divided into four different groups (10 rats/group): control $[0.9 \%$ saline, intraperitoneal (i.p.)], KA (10 $\mathrm{mg} / \mathrm{kg}$ in saline, i.p.), KA (10 $\mathrm{mg} / \mathrm{kg}$, i.p.) preceded by butyrate $(1.5 \mathrm{~g} / \mathrm{kg}$, i.p), and $\mathrm{KA}$ (10 $\mathrm{mg} / \mathrm{kg}$, i.p.) preceded by butyrate $(1.5 \mathrm{~g} / \mathrm{kg}$, i.p). The seizures were terminated by diazepam (10 mg/kg, i.p.; Wako) after status epilepticus lasting $1 \mathrm{~h}$. Sodium butyrate (Sigma, St. Louis, MO, USA) was dissolved in $0.9 \%$ saline $(w / v)$ and injected 10 min prior to the $\mathrm{KA}$ injection. The seizures induced by $K A$ were recorded every $15 \min$ for $2 \mathrm{~h}$.

\section{Western blot analysis}

The rats were culled $2 \mathrm{~h}$ after the injection of KA. The hippocampi were then quickly extracted and homogenised. The total protein was extracted and mixed in $2 \times$ Laemmli buffer (Biorad, Germany) followed by treatment at $99^{\circ} \mathrm{C}$ for about 5 min for denaturation. A quantity $(15 \mu \mathrm{g})$ of protein was separated using $10 \%$ (v/v) sodium dodecyl sulphate-polyacrylamide gel electrophoresis (SDS-PAGE) and transferred by nitrocellulose transfer packs (Biorad). The nitrocellulose membranes were then blocked with $5 \%(w / v)$ skim milk at room temperature for $2 \mathrm{~h}$. The membranes were then treated with the following primary antibodies at $4{ }^{\circ} \mathrm{C}$ overnight: anti-p-ERK (1:1000; Cell Signaling, Boston, MA, USA), anti-GFAP (1:500; Sigma \#G3893), or glyceraldehyde 3-phosphate dehydrogenase (anti-GAPDH 1:2000; Cell Signaling Technology \#2118, USA). The next day, the membranes were washed three times in TBST. Then, the membranes were treated with horseradish peroxidase (HRP)-conjugated secondary antibody (1:2000; Sigma) for $2 \mathrm{~h}$ at room temperature, followed by three washes in TBST. Bands were visualised using enhanced chemiluminescence reagent (ECL, Biorad) in accordance with the manufacturer's protocol. The band intensities were quantified using ImageJ software (NIH, USA). GAPDH was used as a control.

\section{Cell culture}

Primary glial cells were obtained from the brains of postnatal (P0-P2) SD rats. The cells were cultured in an incubator at $37{ }^{\circ} \mathrm{C}$ with $5 \% \mathrm{CO}_{2}$. Astrocytes reached confluency after incubation in Dulbecco's modified Eagle's medium for about 4-5 days. Microglial cells and oligodendroglia were separated from the adherent astrocytes by gentle shaking. The percentage of microglial cells in the co-cultures ranged from $5 \%$ (M5; under physiologic conditions) to $30 \%$ (M30; under cerebral inflammation). Confluent cocultures were detached using trypsin-EDTA (0.1 $\%$ ) and placed on poly-L-lysine-coated cover slips $\left(6 \times 10^{4}\right.$ cells/cover slip, $\left.12 \mathrm{~mm}^{2}\right)$.

Astroglial cells were untreated or treated with $100 \mu \mathrm{M}$ KA alone, $100 \mu \mathrm{M}$ KA preceded by 20 $\mathrm{nM}$ butyrate, or $100 \mu \mathrm{M}$ KA preceded by $200 \mathrm{nM}$ butyrate. Treatment with butyrate was performed 10 min prior to KA treatment. The cells were treated with KA for $24 \mathrm{~h}$ and then collected. Lysates were used for protein analysis.

\section{Statistical analysis}

The results were analysed using GraphPad Prism 5 and expressed as the mean \pm SEM. Two-way analysis of variance (ANOVA) followed by Dunnett's post hoc test was applied for 
comparisons. The threshold for statistical significance was $\mathrm{P}<0.05$.

\section{RESULTS}

\section{Butyrate attenuates KA-induced epileptic behaviour in rats}

Most rats developed continuous convulsive seizures that lasted approximately $60 \mathrm{~min}$. The seizures were accompanied by salivation, forelimb clonus, and rearing. Compared with the control group, rats injected with $10 \mathrm{mg} / \mathrm{kg}$ had significantly increased epileptic responses. The increase peaked at $60 \mathrm{~min}$ after KA injection, followed by a gradual reduction until $2 \mathrm{~h}$ after $\mathrm{KA}$ injection. Treatment with butyrate $(1.5 \mathrm{~g} / \mathrm{kg}$ or 3 $\mathrm{g} / \mathrm{kg}$ ) attenuated the KA-induced epileptic responses, and the effect was dose dependent (Figure 1).

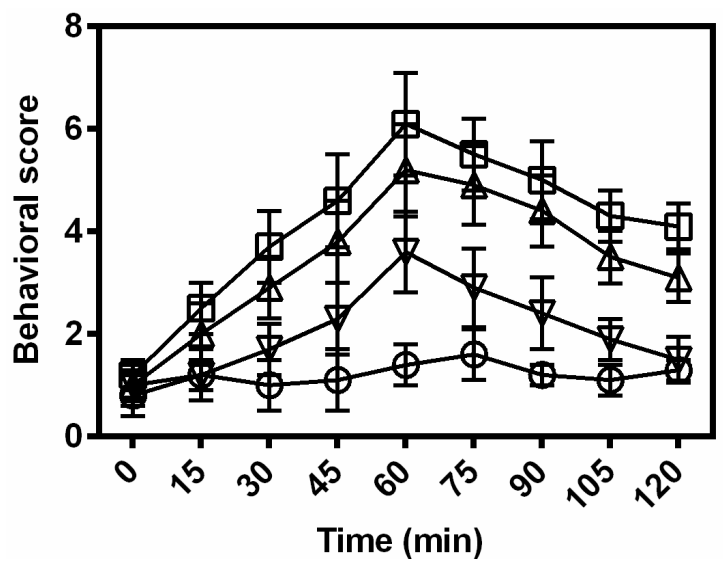

Figure 1: Effects of butyrate on KA-induced epileptic behaviour. Rats were injected i.p. with $0: 0.9 \%$ saline $(\mathrm{n}=10), \square: 10 \mathrm{mg} / \mathrm{kg} \mathrm{KA}$ alone $(\mathrm{n}=10), \Delta: 10 \mathrm{mg} / \mathrm{kg}$ $\mathrm{KA}+1.5 \mathrm{~g} / \mathrm{kg}$ butyrate $(\mathrm{n}=10)$, or $\nabla: 10 \mathrm{mg} / \mathrm{kg} \mathrm{KA}+$ $3.0 \mathrm{~g} / \mathrm{kg}$ butyrate $(\mathrm{n}=10)$. Behaviour scores were recorded over $2 \mathrm{~h}$ ( $\mathrm{n}=10$ in each group). Data are expressed as the mean \pm SEM

\section{Butyrate inhibited KA-induced, seizure- related proteins in rats}

Western blot analysis showed that the KAtreated rats had significantly increased levels of $p$-ERK and GFAP $(p<0.05)$. The induction of $p$ ERK and GFAP was reduced in the butyratetreated rats $(p<0.05$; Figure 2$)$. Given that gliosis is induced by $K A$, which is evidenced by increased GFAP, these data suggest that butyrate treatment induced a reduction in astrogliosis in the KA-treated rats.

Butyrate inhibits KA-induced activation of seizure-related proteins in astrocytes

Butyrate treatment (20 nM or $200 \mathrm{nM}$ ) attenuated the increases in p-ERK and GFAP induced by $\mathrm{KA}$ in a dose-dependent manner (Figure 4).

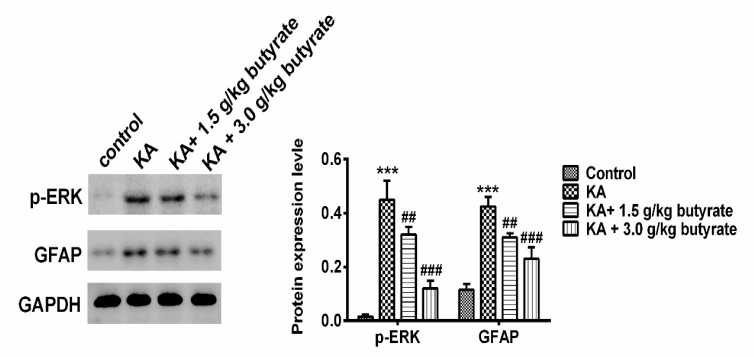

Figure 2: Effects of butyrate on $p$-ERK and GFAP in $K A$-induced rats. (A) Western blot analysis using anti$\mathrm{p}$-ERK and anti-GFAP antibodies of hippocampus extracts from rats treated with saline, $10 \mathrm{mg} / \mathrm{kg} \mathrm{KA}, 10$ $\mathrm{mg} / \mathrm{kg} \mathrm{KA}+1.5 \mathrm{~g} / \mathrm{kg}$ butyrate, or $10 \mathrm{mg} / \mathrm{kg} \mathrm{KA}+3.0$ $\mathrm{g} / \mathrm{kg}$ butyrate. (B) Quantification of $\mathrm{p}$-ERK and GFAP levels relative to GAPDH. Data are presented as the mean \pm SEM. ${ }^{* * *} \mathrm{KA}$ vs. control; \#\# KA + $1.5 \mathrm{~g} / \mathrm{kg}$ butyrate vs. KA; \#\#\# KA + $3.0 \mathrm{~g} / \mathrm{kg}$ butyrate vs. KA

Butyrate inhibits KA-induced proinflammatory cytokine production in rat models

Rats treated with KA alone exhibited higher IL-1ß levels $(p<0.05)$ than those in the control group. Treatment with $1.5 \mathrm{~g} / \mathrm{kg}$ or $3 \mathrm{~g} / \mathrm{kg}$ butyrate resulted in lower IL-1B levels in a dosedependent manner (Figure 3).

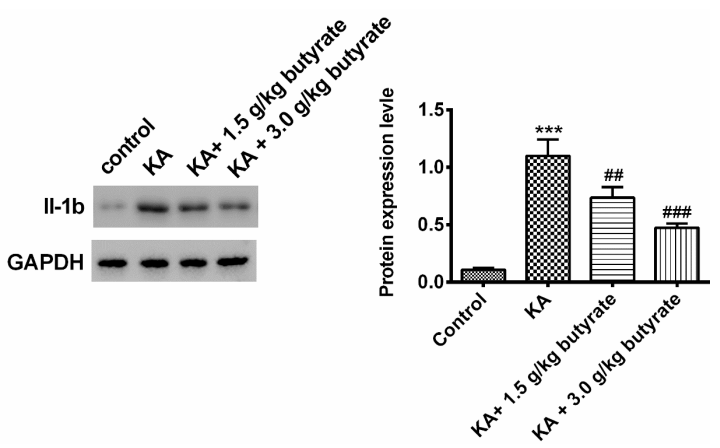

Figure 3: Effects of butyrate on KA-induced inflammation. (A) Western blot analysis of IL-1B in hippocampus extracts from rats treated with saline, 10 $\mathrm{mg} / \mathrm{kg} \mathrm{KA}, 10 \mathrm{mg} / \mathrm{kg} \mathrm{KA}+1.5 \mathrm{~g} / \mathrm{kg}$ butyrate, or 10 $\mathrm{mg} / \mathrm{kg} \mathrm{KA}+3.0 \mathrm{~g} / \mathrm{kg}$ butyrate. (B) Quantification of IL$1 B$ levels relative to GAPDH. Data are presented as the mean \pm SEM. ${ }^{* * *} \mathrm{KA}$ vs. control; \#\# KA + $1.5 \mathrm{~g} / \mathrm{kg}$ butyrate vs. KA; \#\#\# KA + $3.0 \mathrm{~g} / \mathrm{kg}$ butyrate vs. KA

\section{Butyrate inhibits KA-induced proinflamma- tory cytokine expression in rat astrocytes}

KA-treated astrocytes expressed increased levels of IL-1B $(p<0.05)$ compared with untreated astrocytes. The increase in IL-1ß was significantly attenuated in cells pre-treated with butyrate (20 or $200 \mathrm{nM}$ ) prior to KA treatment (Figure 5). 


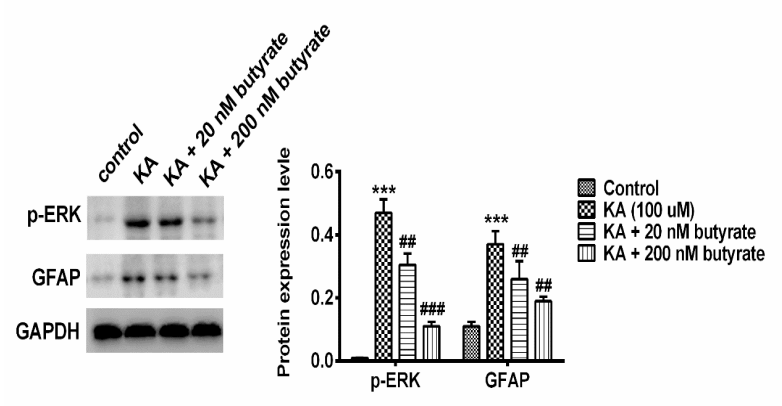

Figure 4: Effects of butyrate on $p$-ERK and GFAP levels in KA-induced astrocytes. (A) Western blot analysis using anti-p-ERK and anti-GFAP antibodies of astrocytes treated with saline, $100 \mu \mathrm{M}$ KA, $100 \mu \mathrm{M}$ $\mathrm{KA}+20 \mathrm{nM}$ butyrate, or $100 \mu \mathrm{M} \mathrm{KA}+200 \mathrm{nM}$ butyrate. (B) Quantification of $p$-ERK and GFAP levels relative to GAPDH. Data are presented as the mean \pm SEM. ${ }^{* * *} \mathrm{KA}$ vs. control; \#\# KA +20 nM butyrate vs. $\mathrm{KA}$; \#\#\# KA + 200 nM butyrate vs. KA

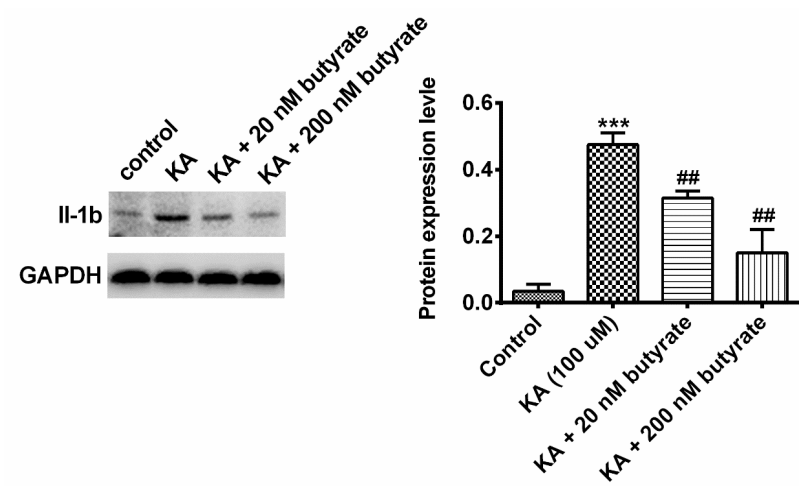

Figure 5: Effects of butyrate on IL-1ß in KA-induced astrocytes. Astrocytes were untreated, treated with $100 \mu \mathrm{M} \mathrm{KA}$ alone, or treated with $100 \mu \mathrm{M} \mathrm{KA}$ preceded by $20 \mathrm{nM}$ or $200 \mathrm{nM}$ butyrate. Treatment with butyrate was performed 10 min prior to KA treatment. (A) IL-1B expression was determined by Western blot analysis. Immunoblots are representative of three independent experiments. (B) Quantification of IL-1B levels relative to GAPDH. Data are presented as the mean \pm SEM. *** KA vs. control; \#\# KA + 20 nM butyrate vs. KA; \#\#\# $K A+200$ nM butyrate vs. KA

\section{DISCUSSION}

The findings characterised the effects of butyrate on KA-induced epilepsy in rat and cell models of acute seizure by evaluating multiple parameters, including behavioural seizure scores and the levels of a seizure-related indicator ( $p$-ERK), a proinflammatory cytokine (IL-1B), and an astrogliosis marker (GFAP). The results provide evidence for the first time to indicate that butyrate inhibits KA-induced seizures.

$\mathrm{KA}$, an analogue of glutamate, is widely applied for the induction of behavioural/electrophysiological seizures [14]. KA-induced seizures result in neuronal death due to over-activation of glutamate receptors [15]. KA also leads to astrogliosis in the hippocampus $[16,17]$. Sodium butyrate, an epigenetic interventional treatment, has been reported to attenuate stress-induced alteration of the pharmacological action of MK801 [18]. In this study, KA increased behavioural seizure activities and astrogliosis in the hippocampus of rats. Intriguingly, butyrate treatment decreased both of those effects.

Activation of the mitogen-activated protein kinase (MAPK) pathway is involved in cell death or cell survival triggered by KA $[19,20]$. A previous study showed a significant increase in ERK phosphorylation after KA administration [21]. In the present study, rats and rat astrocytes were treated with KA to promote astrocytosis. In both the whole-rat model and the cellular model, KA treatment caused increased GFAP expression, which is consistent with previous findings [20]. Pre-treatment with butyrate led to decreased GFP levels, which suggest reduced astrocytosis in the hippocampi of the rats and in the astrocyte cells.

Epilepsy has been found to be tightly associated with inflammation, as shown by increased expression of proinflammatory cytokines. Proinflammatory cytokines were found to be increased in tissues or cerebral spinal fluid in patients with chronic seizures [22]. The findings of the present study suggest that butyrate could inhibit KA-induced inflammation in rats. The results in astrocytes were consistent with those findings. Thus, the findings in both whole-rat and cellular models suggest that butyrate could inhibit $\mathrm{KA}$-induced inflammation. Animals with a genetic deficiency in IL-1 $\beta$ production or a blockage in IL$1 \mathrm{c}$ production caused by inhibition of caspase (which synthesizes IL-1 $\beta$ ) exhibit significant seizure reduction [23].

\section{CONCLUSION}

The findings provide evidence that butyrate inhibits seizures induced by KA in animal and cellular models. These results highlight the potential of butyrate as a treatment for seizures.

\section{DECLARATIONS}

\section{Conflict of Interest}

No conflict of interest associated with this work.

\section{Contribution of Authors}

The authors declare that this work was done by the authors named in this article and all liabilities 
pertaining to claims relating to the content of this article will be borne by them. Yanwen Lv and Changquan Wang designed all the experiments and revised the paper. Guangming Xia, Gang Li and Changquan Wang performed the experiments, Feng Wan and Zhanchi Xiao wrote the paper.

\section{REFERENCES}

1. Beghi E, Berg A, Carpio A, Forsgren L, Hesdorffer DC, Hauser WA, Malmgren K, Shinnar S, Temkin N, Thurman $D$, et al. Comment on epileptic seizures and epilepsy: definitions proposed by the International League Against Epilepsy (ILAE) and the International Bureau for Epilepsy (IBE). Epilepsia, 2005; 46: 16981699; author reply 1701-1692.

2. Ngugi AK, Bottomley C, Kleinschmidt I, Sander JW, Newton CR. Estimation of the burden of active and lifetime epilepsy: a meta-analytic approach. Epilepsia 2010; 51: 883-890.

3. Schuele SU, Luders HO. Intractable epilepsy: management and therapeutic alternatives. Lancet Neurol 2008; 7: 514-524.

4. Gaitatzis A, Johnson AL, Chadwick DW, Shorvon SD, Sander JW. Life expectancy in people with newly diagnosed epilepsy. Brain 2004; 127: 2427-2432.

5. Pitkanen A, Engel J, Jr. Past and present definitions of epileptogenesis and its biomarkers. Neurotherapeutics 2014; 11: 231-241.

6. Ransohoff RM, Perry VH. Microglial physiology: unique stimuli, specialized responses. Annu Rev Immunol 2009; 27: 119-145.

7. Beach TG, Woodhurst WB, MacDonald DB, Jones MW. Reactive microglia in hippocampal sclerosis associated with human temporal lobe epilepsy. Neurosci Lett 1995; 191: 27-30.

8. Vezzani A, French J, Bartfai T, Baram TZ. The role of inflammation in epilepsy. Nat Rev Neurol 2011; 7: 3140.

9. Vezzani A, Granata T. Brain inflammation in epilepsy: experimental and clinical evidence. Epilepsia 2005; 46 : 1724-1743.

10. Wetherington J, Serrano G, Dingledine R. Astrocytes in the epileptic brain. Neuron 2008; 58: 168-178.

11. Choi J, Koh $S$. Role of brain inflammation in epileptogenesis. Yonsei Med J 2008; 49: 1-18.
12. Wirrell E, Farrell K, Whiting $S$. The epileptic encephalopathies of infancy and childhood. Can $J$ Neurol Sci 2005; 32: 409-418.

13. Mcgrath JC, Drummond GB, Mclachlan EM. Guidelines for reporting experiments involving animals: the ARRIVE guidelines. Bri Pha 2010; 160: 1573-1576.

14. Bunch L, Krogsgaard-Larsen P. Subtype selective kainic acid receptor agonists: discovery and approaches to rational design. Med Res Rev 2009; 29: 3-28.

15. Fujikawa DG. Prolonged seizures and cellular injury: understanding the connection. Epilepsy Behav 2005; 7 Supp/3: S3-11.

16. Chen ZL, Yu H, Yu WM, Pawlak R, Strickland S. Proteolytic fragments of laminin promote excitotoxic neurodegeneration by up-regulation of the KA1 subunit of the kainate receptor. J Cell Biol 2008; 183: 12991313.

17. Liang LP, Patel $M$. Seizure-induced changes in mitochondrial redox status. Free Radic Biol Med 2006; 40: 316-322.

18. Deutsch SI, Rosse RB, Long KD, Gaskins BL, Burket JA, Mastropaolo J. Sodium butyrate, an epigenetic interventional strategy, attenuates a stress-induced alteration of MK-801's pharmacologic action. Eur Neuropsychopharmacol 2008; 18: 565-568.

19. Ferraguti F, Corti C, Valerio E, Mion S, Xuereb J. Activated astrocytes in areas of kainate-induced neuronal injury upregulate the expression of the metabotropic glutamate receptors 2/3 and 5. Exp Brain Res 2001; 137: 1-11.

20. Ferrer I, Blanco R, Carmona M, Puig B, Dominguez I, Vinals F. Active, phosphorylation-dependent MAP kinases, MAPK/ERK, SAPK/JNK and p38, and specific transcription factor substrates are differentially expressed following systemic administration of kainic acid to the adult rat. Acta Neuropathol 2002; 103: 391 407.

21. Crespo-Biel N, Canudas AM, Camins A, Pallas $M$. Kainate induces $A K T, E R K$ and cdk5/GSK3beta pathway deregulation, phosphorylates tau protein in mouse hippocampus. Neurochem Int 2007; 50: 435-442.

22. Aronica E, Crino PB. Inflammation in epilepsy: clinical observations. Epilepsia 2011; 52 Supp/ 3: 26-32.

23. Dube C, Vezzani A, Behrens M, Bartfai T, Baram TZ. Interleukin-1beta contributes to the generation of experimental febrile seizures. Ann Neurol 2005; 57: 152155. 